Revista Tecné, Episteme y Didaxis: TED. Año 2014, Número

Extraordinario. ISSN Impreso: 0121-3814, ISSN web: 2323-0126

Memorias, Sexto Congreso Internacional sobre Formación de Profesores de Ciencias. 08 al 10 de octubre de 2014, Bogotá

\title{
Observatório da Educação com foco em Matemática e iniciação às ciências: articulação entre a formação de professores, alfabetização científica e QSC
}

Troian, Thiélide Veronica da Silva P.1, Kochhann, Maria Elizabete Rambo², Teixeira, Solange Ramos ${ }^{3}$

Categoria 1. Reflexões e experiências de inovação na sala de aula.

\section{Resumo}

O texto que se apresenta é um relato de experiência de atividades desenvolvidas por professores, participantes do projeto Observatório da Educação (OBEDUC), com alunos na produção de sabão. Em um desses experimentos foram utilizados os recipientes para acondicionamento do mesmo fazendo uso da reutilização de garrafas Pets recolhidas na comunidade. O objetivo foi oportunizar a estudantes uma percepção da integração com as relações sociais e o ambiente se evidencia nas experiências vivenciadas pelos alunos e professores por meio das Questões Sócio-científicas. Tal proposta justifica-se pelo fato de que, ao desenvolver atividades como essas Ihes são oportunizadas subsídios para a compreensão dos fenômenos físicos, ambientais e sociais da região em que se vive. O referencial teórico é pautado em Orquiza-de-Carvalho e Carvalho (2012), entre outros.

\section{Palavras-Chave}

Alfabetização científica, formação de professores, questão sócio-científica.

\section{Introdução}

No Brasil, atualmente diversas políticas públicas têm fomentado ações que visam o estreitamento das relações entre as Universidades e as Escolas de Educação Básica, um dos focos principais dessas ações é oportunizar aos professores em formação estudantes de licenciaturas, o contato com os professores experientes, com o objetivo de que este contato se configure como momentos formativos para ambos.

\footnotetext{
1 Universidade do Estado de Mato Grosso. thielide@unemat.br

2 Universidade do Estado de Mato Grosso. beterambo@gmail.com

3 Secretaria de Estado de Educação. solangejacobino@hotmail.com
} 
Revista Tecné, Episteme y Didaxis: TED. Año 2014, Número Extraordinario. ISSN Impreso: 0121-3814, ISSN web: 2323-0126

Memorias, Sexto Congreso Internacional sobre Formación de Profesores de Ciencias. 08 al 10 de octubre de 2014, Bogotá

Projetos como o Observatório da Educação fazem parte da atual política educacional do Brasil, pois sua estrutura organizacional possibilita o trabalho coletivo de diversos sujeitos: professores pesquisadores das universidades, estudantes de pós-graduação, estudantes de licenciaturas e professores da Educação Básica, todos com o objetivo de melhorar a qualidade da educação brasileira oferecida aos alunos, principalmente das escolas de regiões periféricas e com baixo rendimento nas avaliações de larga escala.

Neste contexto, a finalidade do Observatório da Educação com foco em Matemática e iniciação às Ciências, enquanto política pública é promover a capacitação de professores e a disseminação de conhecimentos sobre educação e ciência, além de fortalecer o diálogo entre a comunidade acadêmica, os gestores das políticas nacionais de educação e os diversos atores envolvidos no processo educacional, tendo como ação a formação de recursos humanos capacitados para atuação nas áreas de gestão de políticas educacionais, avaliação educacional e formação de docentes.

O relato que ora apresentamos é fruto das ações realizadas pelos participantes do Projeto Observatório da Educação com Foco em Matemática e Iniciação em Ciências, que compõe um Núcleo em Rede, constituído por três Instituições de Ensino Superior brasileiras: a Universidade Estadual Paulista - UNESP - Campus de llha Solteira, a Universidade do Estado de Mato Grosso - UNEMAT, e a Universidade Federal de Mato Grosso - UFMT, onde pesquisadores-bolsistas nesse núcleo atualmente, três doutorandos, nove mestrandos, dezoito licenciandos, dezoito professores da educação básica e três docentes orientadoras, sendo esse número proporcional em cada IES. Também participam como pesquisadores colaboradores vários professores das IES.

As ações que relataremos foram desenvolvidas pelos pesquisadores da UNEMAT nas diversas escolas parceiras onde o OBEDUC atua desde o ano de 2011 com ações intensas que objetivam a alteração dos índices de desempenho dos alunos na Prova Brasil, uma avaliação em larga escala que é aplicada aos alunos do Ensino Fundamental no Brasil. Para alterar o desempenho dos alunos e elevar o Índice de Desempenho da Educação Básica - IDEB das escolas parceiras é necessário investir desde cedo na educação científica, sendo importante para tal trabalhar na formação dos professores neste sentido. 
Revista Tecné, Episteme y Didaxis: TED. Año 2014, Número Extraordinario. ISSN Impreso: 0121-3814, ISSN web: 2323-0126

Memorias, Sexto Congreso Internacional sobre Formación de Profesores de Ciencias. 08 al 10 de octubre de 2014, Bogotá

A qualidade da educação que buscamos está imbricada na formação cidadã de nossos alunos, essa formação prescinde a leitura crítica do mundo, o exercício da autonomia e o desenvolvimento da capacidade de buscar soluções, dessa maneira, acreditamos que podemos contribuir trazendo a ciência para o cotidiano dos alunos durantes as aulas na educação básica, pois conhecimento não se constrói de um dia para o outro, ou seja, a formação de cidadãos críticos e questionadores deve ser trabalhada continuamente.

Através de ações formativas com os professores, buscamos, num processo dialético, fomentar experiências de inovação na sala de aula, onde o potencial curioso, criativo e inventivo dos alunos seja valorizado. É um grande desafio, num processo permeado por avanços e retrocessos e o componente principal é o professor perceber-se num aprendizado continuo, ou seja, em formação permanente.

Neste contexto, trazemos recortes de algumas experiências vivenciadas pelos pesquisadores do OBEDUC, alunos da educação básica e seus professores. Nossa intenção é oportunizar reflexões acerca do processo formativo vivido pelos diversos atores das ações em relação à Alfabetização Científica e as Questões Sociocientíficas, processo esse em constante construção, avaliação e reelaboração.

\section{Desenvolvimento}

Para os alunos a ciência ganha um novo significado a partir do momento em que fornece subsídios para a compreensão dos fenômenos físicos, ambientais e sociais da região em que se vive. Destarte a abordagem de Questões sócio-científicas se configura como um aporte de contextualização dos conteúdos curriculares a serem trabalhados pela escola, pois leva em consideração o contexto em que as escolas estão inseridas e pode ser um fator motivador para a aprendizagem, trazendo consigo o caráter interdisciplinar, pois as aprendizagens são amplas, não se reduzindo a um único componente curricular.

Nesse contexto, partimos da premissa de que o conhecimento científico precisa ser trabalhado de modo a levar o aluno a desenvolver uma visão mais abrangente, subjetiva, que contemple a multiplicidade de relações que se estabelecem em meios às criações científicas, pois:

Não se pode ingenuamente acreditar que a ciência, como um conjunto de conhecimentos (ciência-disciplina) e de atividades (ciência-processo), seja algo 
Revista Tecné, Episteme y Didaxis: TED. Año 2014, Número Extraordinario. ISSN Impreso: 0121-3814, ISSN web: 2323-0126

Memorias, Sexto Congreso Internacional sobre Formación de Profesores de Ciencias. 08 al 10 de octubre de 2014, Bogotá

independente do meio social, alheio a influências estranhas e neutro em relação às várias disputas que envolvem a sociedade. (Freire- Maia, apud Alves e Carvalho, 2012, pág. 228).

Nessa linha de raciocínio, o grande desafio é justamente fazer com que o trabalho de sala de aula tenha algum significado para o aluno, como preconizam Farias e Carvalho (2012, pág. 218): Cientes de desafios epistemológicos e educativos suscitados pelas questões ambientais nos contextos escolares, somos levados a pensar no modo de proceder em direção a uma educação voltada para a compreensão e implicação subjetivas.

No ensino de ciências isso ocorre na medida em que o educando compreende a realidade, por meio de um processo crítico e reflexivo, pois:

A formação crítica implica a capacidade de compreender a ciência como uma atividade humana, ou seja, que o indivíduo possua a capacidade de identificar os produtos da ciência e analisá-los criticamente de modo a perceber, em nível individual, coletivo e ambiental, os possíveis impactos dos artefatos científico-tecnológicos. (Bortoletto e Carvalho, 2012, pág.251).

Nessa perspectiva, o professor não tem o papel de resolver, mas sim de salientar e estimular a busca por parte do aluno, ou seja, fomentar a curiosidade concebida como Paulo Freire (1994) a concebe: "uma necessidade ontológica que caracteriza o processo de criação e recriação da existência humana." (pág.93) Assim, para tanto o professor necessita de algum conhecimento específico sobre o assunto. Um fator importante que destacamos no desenvolvimento do conhecimento do professor é o gerenciamento de processos argumentativos sobre questões controversas. Gerenciar esse processo argumentativo não é uma tarefa fácil, aliás, é uma problemática imensa, mas cabível, pois afinal, qual é a verdade? A resposta certa? Qual é o conhecimento pedagógico que o professor tem que ter pra apresentar informações controversas?

Outra característica própria das QSC é o tratamento interdisciplinar, que fica evidente, pois esta torna-se requisito para uma visão da realidade nas perspectivas da unidade e da totalidade do real. Mas como o professor ganha autorização para 
Revista Tecné, Episteme y Didaxis: TED. Año 2014, Número Extraordinario. ISSN Impreso: 0121-3814, ISSN web: 2323-0126

Memorias, Sexto Congreso Internacional sobre Formación de Profesores de Ciencias. 08 al 10 de octubre de 2014, Bogotá

falar de outras coisas que não são da disciplina dele? Que tipo de conhecimento pedagógico é preciso desenvolver para trabalhar com estas questões? Assim,

Para que se possa estudar um caso e surpreender-se com os sentidos que se produzem a partir dele, numa abordagem interpretativa, parece ser necessário passar por esta etapa de compreendê-lo. [...] Talvez a maior contribuição que os casos podem sugerir para a educação CTSA e mesmo para a EA é a oportunidade de desenvolver aprendizagens que evidenciem a perspectiva investigativa da realidade, assim, como as questões de ordem ética, moral e política. (Farias e Carvalho, 2012, pág. 220).

Desse modo, o processo interpretativo de um determinado caso pode oportunizar ao educando perceber-se como parte integrante dele, na medida em que se vê e compreende a rede de relações que o compõe, ou seja, a complexidade que constitui as relações sociais com o ambiente e as controvérsias presentes.

A percepção da integração com as relações sociais e o ambiente se evidencia nas experiências vivenciadas pelos alunos e professores por meio das Questões Sóciocientíficas no OBEDUC, entre elas, a desenvolvida por um professor de química que também é integrante do projeto OBEDUC - junto aos seus alunos de $1^{\circ}$ e $2^{\circ}$ anos do Ensino Médio de uma escola pública de Rondonópolis/MT onde o foco principal foi o reaproveitamento do óleo de cozinha proveniente de frituras realizadas pela comunidade para ser utilizado na fabricação de sabão, esse foi um momento muito rico para a construção do conhecimento, pois através da experimentação puderam presenciar a ocorrência de uma transformação química, e no decorrer da atividade, houve o momento propício para serem trabalhados alguns conteúdos que fazem parte da matriz curricular da disciplina, além da discussão acerca das questões ambientais relacionadas ao descarte inadequado do óleo.

Outra experiência com o mesmo enfoque, mas com outros desdobramentos, foi vivenciada em uma escola da zona rural do município de Barra do Bugres/MT, onde além da fabricação de sabão, os recipientes para acondicionamento do mesmo se deu por meio da reutilização de garrafas Pets recolhidas na comunidade, ou seja, ao tratarmos da reutilização de materiais que possivelmente seriam jogados na 
Revista Tecné, Episteme y Didaxis: TED. Año 2014, Número Extraordinario. ISSN Impreso: 0121-3814, ISSN web: 2323-0126

Memorias, Sexto Congreso Internacional sobre Formación de Profesores de Ciencias. 08 al 10 de octubre de 2014, Bogotá

natureza pelos alunos, mostramos algumas possibilidades de aproveitamento desses materiais.

Na organização das atividades desenvolvidas nas escolas buscamos aporte nos escritos de María Pilar Jiménez Aleixandre em seu texto: A argumentação sobre questões sócio-científicas: processos de construção e justificação do conhecimento na aula, onde a autora explicita os procedimentos necessários na construção de um ambiente de aprendizagem propício para a discussão das Questões Sóciocientíficas:

O ambiente de aprendizagem implica que os estudantes participaram em tarefas desenhadas como problemas autênticos. Estes são tarefas que 1) têm carácter problemático (é dizer não uma solução obvia), 2) carácter aberto, é dizer mais de uma solução possível, e distintos caminhos para chegar a ela; 3) contexto real, é dizer que o alunado podia percebe-lo como relevantes para ás suas vidas e 4) que o trabalho para resolve-lo seja coerente coa forma de trabalhar da comunidade científica, apelando a dados para sustentar enunciados, justificando as hipóteses etc. (2013, pág.271)

As experiências formativas vivenciadas pelos pesquisadores do OBEDUC são diversas e muito ricas, permeadas pela intenção de oportunizar a todos os envolvidos a alfabetização científica por meio das Questões Sócio-científicas, tendo sua gênese na formação de professores proposta nas escolas parceiras. É importante salientar que a aprendizagem dos conteúdos disciplinares não se resumem ao processo e ao produto, mas abrange também a sua gênese e historicidade, o que implica em revisitar a ciência, reinterpretar o que sabemos, com vistas aos seus aportes históricos, psicogenéticos, sociogenéticos e políticos que estes conceitos científicos implicam, seja no seu produzir, no seu divulgar e no seu fazer.

\section{Conclusão}

Enquanto equipe de pesquisadores nos encontramos no processo inicial em relação as aprendizagens e trabalho pedagógico com a alfabetização científica e as QSCs, por isso ainda vivenciamos desafios de diversas ordem, entretanto, principalmente nos momentos formativos vivenciados com os professores no Grupos de Estudos das escolas parceiras, buscamos evidenciar as potencialidades, principalmente em 
Revista Tecné, Episteme y Didaxis: TED. Año 2014, Número Extraordinario. ISSN Impreso: 0121-3814, ISSN web: 2323-0126

Memorias, Sexto Congreso Internacional sobre Formación de Profesores de Ciencias. 08 al 10 de octubre de 2014, Bogotá

relação a importância de investigar e agir simultaneamente com todos os envolvidos no processo educativo, com a intenção de transformar os modos de perceber a realidade criticamente, função importante da educação como um todo e principalmente da Educação para as ciências.

Em suma, precisamos formar os cidadãos com ferramentas capazes de fazer as leituras necessárias que envolvam a ciência e a matemática para intervir no mundo com mais consciência e propriedade, esse é o grande desafio da educação na atualidade, para tanto, é necessário inovar, refletir e entender-se em formação permanente.

\section{Referências bibliográficas}

Alves, João A. P. Carvalho, Washington L. P. de. (2012): Significados que alunos do ensino médio atribuem à ciência e tecnologia pela vivência de diferentes perspectivas de um caso de dano socioambiental. In: Formação de professores e questões sócio-científicas no ensino de ciências. Org. Lizete Maria Orquiza-de-Carvalho e Washington L. P. de Carvalho. São Paulo: Escrituras Editora, 2012. P. 225-247.

Bortoletto, Adriana. Carvalho, Washington L. P. de.(2012) Temas sociocientíficos: análise dos processos argumentativos no contexto escolar. In: Formação de professores e questões sócio-científicas no ensino de ciências. Org. Lizete Maria Orquiza-de-Carvalho e Washington L. P. de Carvalho. São Paulo: Escrituras Editora, P. 249-269.

Farias, Carmen. R. de O. Carvalho, Washington L. P. de. (2012) Do arquivo à escola: interpretações em torno de um caso controverso de direito ambiental no ensino médio. In: Formação de professores e questões sócio-científicas no ensino de ciências. Org. Lizete Maria Orquiza-de-Carvalho e Washington L. P. de Carvalho. São Paulo: Escrituras Editora,. P. 193-221.

Freire, P. (1994): Cartas a Cristina. Ed. Paz e Terra, Rio de Janeiro, RJ.

Jiménez Aleixandre, M.P : (2013) IX Congreso internacional sobre investigación en didáctica de las ciencias (2013): 272-284 